\section{Coronavirus Antibodies in Bat Biologists}

To the Editor: Severe acute respiratory syndrome-associated coronavirus (SARS-CoV) is a new coronavirus that caused an epidemic of 8,096 cases of SARS and 774 deaths during 2002-2003 (1). Attempts are ongoing to identify the natural reservoir of SARS-CoV. Several horseshoe bat species (Rhinolopus spp.) from Asia $(2,3)$ and a sample of bats from Africa (4) have been found to be infected by and potential reservoirs for various SARS-like CoVs and various CoVs that are not SARS-like (2-4). However, transmission of bat SARS$\mathrm{CoV}$ from bats to humans has not been reported.

During October 2005, we looked for serologic evidence of infection among bat biologists attending an international meeting in the United States. After giving informed consent, volunteer biologists completed an anonymous survey and provided $10 \mathrm{~mL}$ of blood. Serum samples were tested at the Centers for Disease Control and Prevention (CDC) for antibodies against inactivated human SARS-CoV and against recombinant, expressed SARS-CoV nucleocapsid protein (SARS-CoV N) by enzyme immunoassays (EIAs) as described $(5,6)$. This study was approved by the CDC Institutional Review Board.

Of 350 registered biologists, 90 (26\%) participated. Of participants, $89 \%$ had worked with or studied bats in North America, 21\% in South America, $11 \%$ in Africa, $8 \%$ in Asia, $7 \%$ in Europe, and 6\% in Australia. The primary genera studied by participants were Myotis (24\%), Tadarida (13\%), and Eptesicus (10\%). A total of $20(23 \%)$ participants had worked with or had contact with horseshoe bat species (Rhinolopus spp.). Because this genus has 69 species, distributed from Australia to Europe, some participants who indicated that they worked with the Rhinolopus spp. may likely have worked with species found outside of Asia. Involvement with bats most often consisted of capturing or handling them in the field $(90 \%)$, followed by capturing or handling them in the laboratory (36\%). Urine and feces were encountered most frequently ("always" or "most of the time" by 66\%-68\% of participants); contact with blood, saliva, or tissues and bites or scratches reportedly occurred less often ("always" or "most of the time" by $4 \%-28 \%$ of participants).

The serum samples from all 90 participants were negative for antibodies against inactivated SARS$\mathrm{CoV}$, and samples from all but 1 were negative for SARS-CoV N protein. The 1 positive sample gave a strong signal (optical density 1.08 at $405 \mathrm{~nm}$ at a 1:400 dilution) by SARS-CoV N protein EIA and against SARS-CoV $\mathrm{N}$ by Western blot but gave no reactivity against recombinant SARS$\mathrm{CoV}$ spike protein or inactivated SARS-CoV by either EIA or Western blot. Because the $\mathrm{N}$ protein has a region that is relatively conserved among all known coronaviruses (7), the antibodies against SARS-CoV N protein could have been induced by other CoVs. Previous studies have demonstrated that SARS-CoV N protein can cross-react with polyclonal antiserum induced by group 1 animal CoVs (8).

To address the possibility that the antibodies from this serum sample were not specific to SARS-CoV, we tested it against recombinant $\mathrm{N}$ proteins of human CoVs, HCoV-229E, HCoVOC43, NL63, and HKU-1. The serum reacted to all $4 \mathrm{~N}$ proteins, by EIA and Western blot, at titers of 400-1,600. We then tested the sample against 3 recombinant fragments of the $\mathrm{N}$ protein from each of 3 viruses: SARSCoV, HCoV-229E, and HCoV-OC43. One of these fragments, N2, contains a highly conserved motif (FYYLGTGP) that should detect cross-reacting antibodies; the other 2 fragments should detect antibodies specific to the strain or group. The serum reacted to 2 of 3 fragments from $\mathrm{HCoV}-\mathrm{OC} 43$ and $-229 \mathrm{E}$ but to only the N2 fragment with the conserved motif from SARS$\mathrm{CoV}$ (Figure), which suggests that the antibodies against SARS-CoV N were likely induced by a $\mathrm{CoV}$ that was not SARS-like.

If the antibodies were induced by a SARS-like CoV infection, we would expect to have also detected antibodies against recombinant $\mathrm{S}$ protein (9) or recombinant fragments representing antigenically distinct regions of the $\mathrm{N}$ protein of SARS-CoV. We did not detect either; instead, we detected antibodies against the antigenically distinct $\mathrm{N}$ fragments from group 1 and 2 human CoVs. Thus, this survey of a sample of bat biologists, who were exposed primarily to North American bats but also to bats from Asia and Africa, showed no evidence of SARSlike $\mathrm{CoV}$ infection.

Our survey found no evidence of SARS-CoV transmission from bats to humans. However, since the conclusion of this study, Dominguez et al. found coronavirus RNA in bats in North America, particularly Eptesicus fuscus and Myotis occultus (10), 2 species of the genera handled by $25 \%$ of the participants in our survey. Of interest is whether the bat biologists who worked with these bats might be at risk for infection with group 1 bat CoVs. Unfortunately, the high likelihood of infection with human group 1 CoVs will make it difficult to address this question. Additional studies of bat SARS-CoV infections in a larger number of persons who have been in contact with the species found to be positive for SARS-like CoV are needed before the risk for SARS-like $\mathrm{CoV}$ transmission from bats to humans can be clearly understood. 


\section{LETTERS}

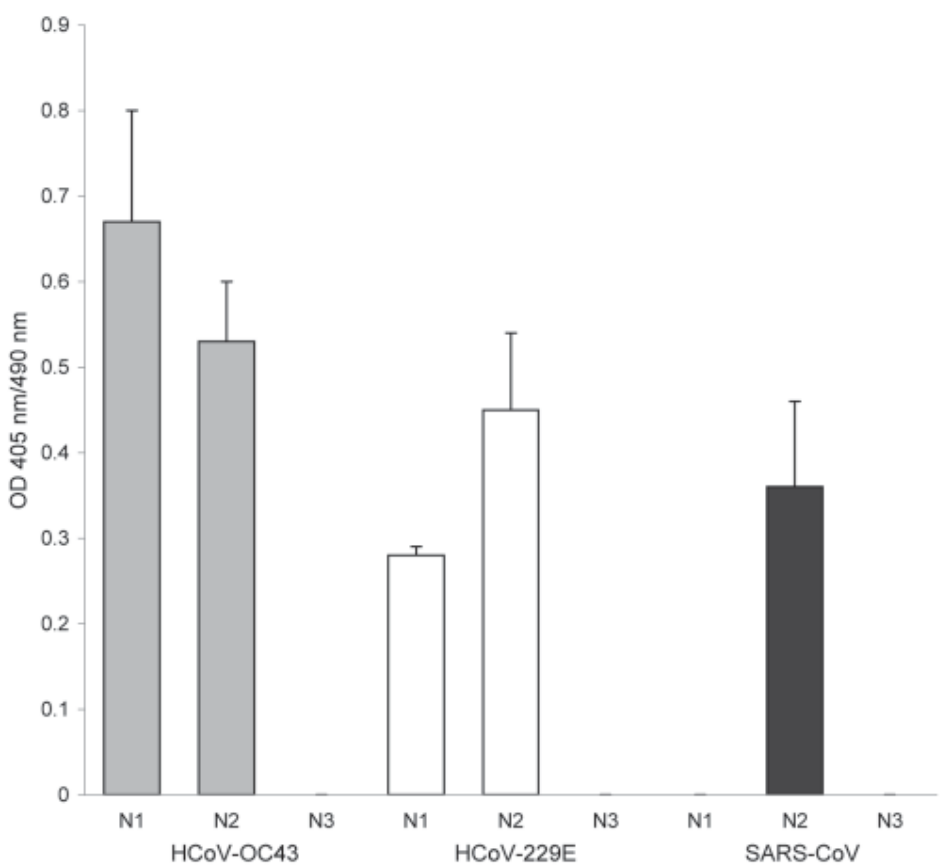

Figure. Antibody reactivity to coronavirus (CoV) nucleocapsid $(\mathrm{N})$ protein fragments by ELISA. A set of recombinant protein fragments covering the $\mathrm{N}$ protein sequence of human $\mathrm{CoV}[\mathrm{HCoV}]-\mathrm{OC} 43, \mathrm{HCoV}-229 \mathrm{E}$, and severe acute respiratory syndrome (SARS)-CoV were used as antigen; the serum (1:400 dilution) from the participant was tested by ELISA. The fragments include the following HCoVs: HCoV-OC43 N1 (aa 1-119), HCoV-OC43 N2 (aa 120-332), HCoV-OC43 N3 (aa 333-448), HCoV-229E N1 (aa 1-74), HCoV-229E N2 (aa 75-311), HCoV-229E N3 (aa 312-389), SARS-CoV N1 (aa 1-105), SARS-CoV N2 (aa 106-324), and SARS-CoV N3 (aa 325-422). The HCoV-OC43, HCoV-229E, and SARSCoV fragments were coated at $4 \times 10^{-7} \mathrm{M}, 2.5 \times 10^{-3} \mathrm{M}$, and $8 \times 10^{-8} \mathrm{M}$, respectively. The $\mathrm{N}$-terminal of the $\mathrm{N}$ protein contains a highly conserved motif (FYYLGTGP) found in all CoVs (7). This conserved motif is found in HCoV-OC43 N2, HCoV-229E N2, and SARSCoV N2 recombinant protein fragments. The sizes of the expressed protein fragments used in this study were confirmed by sodium dodecyl sulfate-polyacrylamide gel electrophoresis. In addition, the reactivity of each protein fragment was confirmed by using Western blot with the anti-His antibody and the respective convalescent-phase serum. The mean optical density (OD) of absorbance at $405 \mathrm{~nm}$ (490-nm reference) of duplicate wells is shown. Error bars represent the standard deviation of duplicate wells.

\section{Lauren J. Stockman, ${ }^{*}{ }^{1}$ Lia M. Haynes, ${ }^{* 1}$ Congrong Miao, ${ }^{*} \dagger$ Jennifer L. Harcourt, ${ }^{*} \dagger$ Charles E. Rupprecht, ${ }^{*}$ Thomas G. Ksiazek, * Terri B. Hyde, ${ }^{*}$ Alicia M. Fry, ${ }^{*}$ and Larry J. Anderson* \\ ${ }^{*}$ Centers for Disease Control and Preven- tion, Atlanta, Georgia, USA; and †Atlanta Research and Education Foundation, De- catur, Georgia, USA}

${ }^{1}$ These authors contributed equally to this article.

\section{References}

1. World Health Organization. Summary of probable SARS cases with onset of illness from 1 November 2002 to 31 July 2003 [cited 2005 Jul 26]. Available from http://www.who.int/csr/sars/country/ table2004 04 21/en/print.html

2. Li W, Shi Z, Yu M, Ren W, Smith C, Epstein $\mathrm{JH}$, et al. Bats are natural reservoirs of SARS-like coronaviruses. Science. 2005;310:676-9.

3. Lau SK, Woo PC, Li KS, Huang Y, Tsoi $\mathrm{HW}$, Wong BH, et al. Severe acute respiratory syndrome coronavirus-like virus in Chinese horseshoe bats. Proc Natl Acad Sci U S A. 2005;102:14040-5.

4. Muller MA, Paweska JT, Leman PA, Drosten C, Grywna K, Kemp A, et al
Coronavirus antibodies in African bat species. Emerg Infect Dis. 2007;13:1367-70.

5. Ksiazek TG, Erdman D, Goldsmith CS, Zaki SR, Peret T, Emery S, et al. A novel coronavirus associated with severe acute respiratory syndrome. N Engl J Med. 2003;348:1953-66.

6. Haynes LM, Miao C, Harcourt JL, Montgomery JM, Le MQ, Dryga SA, et al. Recombinant protein-based assays for detection of antibodies to severe acute respiratory syndrome coronavirus spike and nucleocapsid proteins. Clin Vaccine Immunol. 2007;14:331-3.

7. Rota PA, Oberste MS, Monroe SS, Nix WA, Campagnoli R, Icenogle JP, et al. Characterization of a novel coronavirus associated with severe acute respiratory syndrome. Science. 2003;300:1394-9.

8. Sun ZF, Meng XJ. Antigenic cross-reactivity between the nucleocapsid protein of severe acute respiratory syndrome (SARS) coronavirus and polyclonal antisera of antigenic group I animal coronaviruses: implication for SARS diagnosis. J Clin Microbiol. 2004;42:2351-2.

9. Woo PC, Lau SK, Wong BH, Chan KH, Hui WT, Kwan GS, et al. False-positive results in a recombinant severe acute respiratory syndrome-associated coronavirus (SARS-CoV) nucleocapsid enzyme-linked immunosorbent assay due to $\mathrm{HCoV}-\mathrm{OC} 43$ and HCoV-229E rectified by Western blotting with recombinant SARSCoV spike polypeptide. J Clin Microbiol. 2004;42:5885-8.

10. Dominguez SR, O'Shea TJ, Oko LM, Holmes KV. Detection of group 1 coronaviruses in bats in North America. Emerg Infect Dis. 2007;13:1295-300.

Address for correspondence: Lauren J. Stockman, Centers for Disease Control and Prevention, 1600 Clifton Rd NE, Mailstop F22, Atlanta, GA 30333, USA; email: 1stockman@ cdc.gov

\section{Letters}

Letters commenting on recent articles as well as letters reporting cases, outbreaks, or original research are welcome. Letters commenting on articles should contain no more than 300 words and 5 references; they are more likely to be published if submitted within 4 weeks of the original article's publication. Letters reporting cases, outbreaks, or original research should contain no more than 800 words and 10 references. They may have one Figure or Table and should not be divided into sections. All letters should contain material not previously published and include a word count. 